zogen, sowie mit grubigen Vertiefungen und kleinen höckrigen Hervorragungen versehen, welche den normalen nur zum Theil entsprechen; überall sind sie von feinschwammigem Gefüge. 3) Die spärlichen Reste der beiden Keilbeinflügel, welche eine grosse, unregelmässige aus der Fusion des Foramen rotundum und opticum bervorgegangene 0 effnung äusserlich einfassen und mit den ebenso rudimentären Part. squamos. ossis temporum den vorderen etwas vertieften Theil des Schädelgrundes bilden.

Die Partes orbitariae des Stirnbeins, die Lamina cribrosa des Siebbeins sind defekt. Die Pars frontalis des Stimbeins existirt ebenfalls nur bis zur Glabella und schneidet über derselben linkerseits mit einem stumpfkantigen Rande, rechterseits mit einem muschelförmig nach innen gebogenen Knochenplättchen ab, welches fïr das Resultat einer vom rechtẹ Tuber frontale ausgegangenen Ossification zu halten sein dürfte.

Die Knochen des Gesichts, des Beekens und der Extremitäten sind normal.

3.

Atresie der Scheide mit abnormen Menstrualwegen.

Von Dr. Graf in Elberfeld.

Bertha R., 25 Jahre alt, gracil gebaut, , hysterisch", litt im Mai 1856 an einer ulcerativen Entzündung der Scheide, deren Ursache und Verlauf nicht năber bekannt ist, da weder Untersuchung noch chirurgische Behandlung stattfand. Die unverheirathete Pat. läugnet Schwangerschaft ganz entschieden, giebt dagegen bestimmt den Ahgang einer Geschwulst aus den Geschlechtstheilen an, welche sje als hart, bläulich, birnförmig, gestielt schildert. Gleichviel, ob Abortus oder Neoplasma anzunehmen ist, es trat in Folge jener ulcerativen Entzündung eine Verwachsung des grössten Theils der Scheide ein, wie dies die erste im Julì desselben Jahres vorgenommene Untersuchung zeigle. Als Folge derselben stellte sich nun mit der Retention und Ansammlung des Menstrualblutes ein Cycius der grässlichsten Beschwerden ein, wovon ich neben Leib- und Rückenschmerzen nur hartnäckige Verstopfung, Blutbrechen, Congestionen nennen will. Im August trat zu grosser momentaner Erleichterung der Kranken ein Blutabgang durch den Mastdarm ein, der sich von da ab regelmässig jeden Monat wiederholte und dann jedesmal für einige Wochen den Zustand erträglich machte, doch blieben die periodischen Exacerbationen stets fürchterlich. In Folge dessen ward im März 1857 durch Prof. Busch in Bonn die Operation der Atresie in der Weise versucht, dass ejn Catheter in die Blase und ein Finger des Assistenten in das Rectum eingeführt wurde, um so für das langsame Vordringen mit Messer und Scheere einige Anhalispunkte za haben. Nach meirstündiger Operation warde dieselbe wegen 


\section{9}

zunehmender Dünne der Wandungen und aus furcht vor wichtigeren Verletzungen sistírt, nachdem zwar ein bedeutendes Stück der Scheide geöffnet, doch der Uterus nicht erreicht war. Die Nachbehandlung war von gar keinem Erfolg und die Scheide verwuchs wieder bis auf 1 . Zoll vorn änsseren Eingange. Eine zweite Operation im Juli desselben Jahres hatte das gleiche negative Resultat, und die Kranke wurde als unheilbar entlassen. (Mittheilung von Dr. Fleischer in Bonn.) Im October $1857 \mathrm{kam}$ die Kranke zuerst in meine Behandlung. Ich fand die Scheide etwa $1 \frac{1}{2}$ Zoll über dem Eingang durch festes strahliges Narbengewebe verwachsen; der Uterus war weder durch Bauchdecken noch durch den Mastdarm nachweishar; so in der Remission. In der periodischen Exacerbationszeit, wo die oben genannten Beschwerden auftraten, war der Leib stark aufgetrieben, der sehr geschwellte Uterus hoch im grossen Becken durch die Bauchdecken, so wie auch durcb den Mastdarm, der durch ihn sehr bedeutend comprimirt wurde, za fühlen, bis dann endlich die Blutung durch den Mastdarm allmälige Erleichterung macbte. Trotz der sorgfältigsten Untersuchung mit Finger und Speculum gelang es mir so wenig, als dies in Bonn der Fall gewesen war, eine Communication zwischen Uterus und Bectum resp. eine Oeffnung in letzterem nachzuweisen, und es blieb deswegen dahingestellt, ob die in Rede steliende Blutung, wie allerdings wahrscheinlich, eiue directe uterinale oder eine sogenannte vicariirende hämorrhoidale sei. Meine Hülfe beschränkte sich nehen der Darreichung von evacuirenden und narkotischen Mitteln auf locale Blutentziehungen und Klystiere, letztere mit dem Mutterrobr hoch hinauf in das Hectum applicirt. Die Operation der Atresie, welche Dupuytren in solchen Fällen ganz verwirft, Dieffenbacb, der sie einige Male mit günstigem Erfolge gemacht hat, doch die schwierigste und undankbarste nennt, war zweimal von kunstgeübter Hand obne Erfolg vorgenommen, und konnte ich mich zu einer Wiederholung nicht entschliessen. Als nun Dr. Fischer in Cöln, dem die Kranke vorgestellt ward, sich vorläufig dazu bereit erklärte, ward dieselbe im November 1857 in das dortige Spital gesclickt, kehrte jedoch nach 5 Wochen unverrichteter Sache zurück. Dr. Fiscber sclurieb mir, auch er könne sich niclit entschliessen, ohne Anhaltspunkt zu operiren; el glaube an eine Communication 2wischen Uterus und Rectum, die er jedoch auch nicht entdecken könne; falls es gelänge diese zu finden, so könne man mit einer Sonde den Uterus gegen die Scheide berabdrücken und so die Operation ausführen. - Es trat nun nach dieser Entlassung aus dem Cölner Krankenhause der Bluthuss aus dem Mastdarın ničlt wieder ein, die Leiden der Patientin erreichten eine nie gekannte Höbe und der Tod vornehmlich durch Schmerz und Entkräftung schien unvermeidlich, als sich im Februar 1858, nachdem ich Tags zuvor wegen barınäckiger Verstopfung die den Mastdarm comprimirende Gebärmutter (die bis über den Nabel hinaufreichte) durch ein krummes Mutterrolsr nach vorn gedrängt batte, unter gleicluzeitiger Erleichterung der Kranken eine starke Blutunterlaufung und Schwellung in der linken Hälfte der Nates zeigte. Die Schmerzen der Patientin verloren sich in ähnlicher Weise, wie früher nach den Mastdarmblutungen; die Geschwulst, welche sebr diffus war und keine Fluctuation zeigte, verschwand allmälig; ibr folgten im Marz und April ähniliche sugillirte Anschwellungen unter gleichen Erscheinungen. Die jedesmal 
intendiste Eröffnung der Geschwulst, worauf ieh die Patientin gleich beim ersten Auftreten vorbereitet batte, verschob ich, da die übrigen Erscheinungen nicht dazu drängten, bis circumscripte Form und Fluctuation einen besseren Aphaltspunkt gethen wị̂rden. Im Mai, als dies der Fall und die Geschwulst sehr prominirend und schmerzhaft geworden war, wurde, da ich gerade abwesend, durch einen Collegen ein Einstich gemacht, und es ergoss sich eine enorme Quantität eines sehr dunklen syrupartigen Blutes aus der Oeffnung. Anfangs hielt jch diese durch Pressschwamm, blutige Dilatation etc. offen; später zeigte sich dies unnöthig, und es ergiesst sich zu den regelwässigen Menstrualzeiten eine ziemliche Menge dunklen schmierigen Blutes aus derselben. Dieser künstliche Weg befindet sich etwa 1 Zoll von der Mastdarmöffnung in den linken Nates; ein in denselben eingefübrter elastischer Catbeter dringt ohne Mühe etwas nach rechts und innen sich krümmend, cirea 4 Zoll yor. Gefahr und heftige Schmerzen sind seitdem natürlich beseitigt, wenn auch mehrfach catarrhalische Affection des neugebildeten Ganges, innere Verstopfungen desselben etc. zur Bebandlung kamen, wie sich denn auch jedes sonstige Unwohlsein der Patientin mit alterirter Secretion des neuen Menstrualweges event. der Gebärmutter selbst verbindet. In den letzten Monaten ist einige Male, ohne dass der nene Weg sich verstopft hätte, wieder zur Menstrualzeit Blut aus dem Mastdarm hervorgekommen, doch war dies als Ausnalume zu betrachten und änderte die Function des ersteren nicht.

So hat die Natur hier eine Operation vollendet, vor welcher die Clirurgie wohl wit Recht macht- und rathlos dastand.

4.

\title{
Aente Bronchopneumonie mit Ausgang in eitrige Schmelanng und Tod, hervorgernfen durch ein in den Ram. descend. bronchi dextri gerathenes und eingekeiltes Knochenstück.
}

\author{
Mitgetheilt von Dr. Finke In burg, \\ Assistenzarzt der Prov. Jrren-Heilanstalt zu Siegburg.
}

Die bisher beschriebenen Fäle von entzündlichen Lungenaffectionen, welehe durch fremde in die Luftwege gerathene Körper veranlasst wurden, sind in ihrem Verlaufe so verschiedenartig und einer vollstăndigen semiotischen Beleuchtung so wenig gewürdigt worden, dass der naclfolgende, vom ersten Begiane der Funetionsstörung an genau beobachtete Fall, namentlich seiner symptomatischen Eigenthümlichkeiten wegen sehr lehrreich und der Kenntnissnahme in weiteren ärztlichen Kreisen werth erscheint.

Der 34jährige Barbier Z., von kräftigem Körperbau, seit einigen Jabren an chronischem Bronchialcatarrh leidend, klagte am 8. April a. c., dass ihm ein Kno- 